\title{
OBITUARY
}

\section{ThOMAS WILFRED LETCHWORTH}

T. W. LETCHWORTH, who was for many years consulting surgeon to the Royal Eye Hospital, died in London on July 22, 1954, soon after his eightieth birthday. Born at Brighton and educated privately at Emmanuel College, Cambridge, he studied medicine at St. Bartholomew's Hospital and qualified in 1898. He was admitted F.R.C.S. in 1909, having begun to specialize in ophthalmic surgery soon after his graduation. He held appointments at the Royal Westminster Ophthalmic Hospital, where he worked under Brewerton, and at the Central London Ophthalmic, and Royal Eye Hospitals. From 1919 he was a surgeon at the "Royal Eye"; he retired on reaching the age limit in 1934, but with great humility and helpfulness he remained to act for some time as honorary clinical assistant. He continued in consulting practice until three years ago, when he still kept on a small amount of work " to keep his hand in".

L.H.S. writes: To Letchwcrth a patient was never simply an " interesting eye "; he took a personal interest in all his patients, and during his crowded sessions at the Royal Eye Hospital would ask them about other members of their families whom he remembered from previous visits. His appearance was striking, with a patriarchal white beard and eyes which twinkled benignly behind his glasses. This was combined with a complete lack of formality and an independent assessment of people on their merits, which sometimes proved disconcerting to the self-important.

He had a deep interest in mathematical matters, and this precision of thought he carried into his ordinary life. He was fond of refractive work, which he could execute with unrivalled accuracy at prodigious speed. He was a pioneer worker on muscle-balance, and invented a rotary prism of variable strength which he would demonstrate to admiring but not fully comprehending house-surgeons. He was interested in nystagmus, and it was characteristic that he trained himself to demonstrate voluntary nystagmus in an amazing fashion. As an operator he was unsurpassed in his day. He had a light and exquisite sense of touch which enabled him to succeed in the most delicate manipulations. Yet his good temper was such that he never lost patience when training a beginner.

He was a great lover of chess, in which he achieved considerable distinction. Towards the end of his life he suffered a succession of tiresome and painful illnesses, which his devout Catholicism enabled him to kear with Christian fortitude.

T.M.T. writes: Letchworth was a most unusual and delightful character; he was a keen sportsman and had the most delicate sense of humour, and nothing delighted him so much as a sly leg-pull successfully carried out. Those with whom he came in contact could not fail to be attracted by his kindliness, his unselfishness, and his wide knowledge, which embraced languages and mathematics as well as medicine. To crown his academic career, at the age of 73 , and after two cataract operations, he wrote an original thesis for his M.D., and took his degree on the same day that his son took his M.A. at Cambridge. He was particularly proud of this distinction and was seen only a fortnight before his death wearing his gown at a public function at the Royal Eye Hospital, to the delight of his old colleagues. It is by them that Letchworth will be most missed: his fame as a teacher of ophthalmic surgery will be kept green by the number of operations popularized among them by his teaching, and still often performed by them.

Letchworth was very happily married. His wife died two years ago, leaving two sons and a daughter. One of the greatest of pleasures of his life was that his eldest son rowed in the winning Cambridge crew in 1927 and 1928. Since his wife's death he had been somewhat less alert, though he died, as he had always wished, in a light harness. 